\title{
Preparation of Stereocomplex Polylactide/poly(butylene succinate) Blends by Melt Blending
}

\author{
JENJIRA JIRUM and YODTHONG BAIMARK* \\ Biodegradable Polymers Research Unit, Department of Chemistry, Faculty of Science, \\ Mahasarakham University, Mahasarakham 44150, Thailand. \\ *Corresponding author E-mail: yodthong.b@ msu.ac.th \\ http://dx.doi.org/10.13005/ojc/350306
}

(Received: November 23, 2018; Accepted: May 11, 2019)

\begin{abstract}
Biodegradable polymer blends based on stereocomplex polylactide (SCPLA) and poly (butylene succinate) (PBS) were successfully formed by continuous two-step melt blending. An epoxy-based, multifunctional chain extender was chosen to enhance phase compatibility of the blends. Effects of PBS and chain extender on thermal, phase morphology, thermo-mechanical and tensile properties of the scPLA/PBS blends were determined. The PBS blending enhanced plasticizing effect and cold-crystallization of ScPLA matrix in an amorphous region. The chain-extension reaction inhibited crystallization of PBS, PLA homo-crystallites and PLA stereocomplex-crystallites as well as reduced thermal stability of the SCPLA/PBS blends because of formation of long-chain branched structures. It has been shown that the poor phase compatibility between continuous SCPLA and dispersed PBS phases of the blends may be solved through melt blending with a chain extender. The chain extension of scPLA/PBS blends also improved thermo-mechanical properties and flexibility of the ScPLA/PBS blend films.
\end{abstract}

Keywords: Polylactide, Stereocomplex, Poly(butylene succinate), Polymer blends, Chain extender, Thermal properties.

\section{INTRODUCTION}

Poly(L-lactide) (PLLA) bioplastics have extensively investigated because of its biodegradability, renewability, good processability and low toxicity. ${ }^{1-4}$ High-performance bioplastics of enantiomeric PLLA/ poly(D-lactide) (PDLA) blends called as stereocomplex polylactides (SCPLA) have been extensively reported. ${ }^{5-7}$ The ScPLA exhibited higher mechanical properties, better heat-resistance, faster crystallization rate and slower hydrolysis than the PLLA. ${ }^{8-10}$ This is due to the
scPLA had stronger intermolecular forces between PLLA and PDLA chains. ${ }^{8,11}$

The PLLA has been melt-blended with a flexible poly(butylene succinate) (PBS) to enhance flexibility and toughness as well as maintain complete biodegradability. ${ }^{12-16}$ The PBS could form a miscible blend with PLLA in the amorphous region and enhanced the crystallization of PLLA matrix. However, scPLA/PBS blends have not been reported so far.

This is an Open Access article licensed under a Creative Commons license: Attribution 4.0 International (CC- BY). Published by Oriental Scientific Publishing Company @ 2018

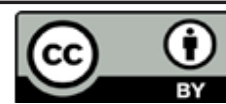


Joncry $\left.\right|^{\circledR}$ have been used as effective chain-extenders for producing long-chain branching PLLA during melt process to maintain its molecular weight. ${ }^{17-19}$ However the effect of chain extender on properties of SCPLA/PBS blends have not been published. Therefore the influences of PBS and chain extender on stereocomplexation and properties of scPLA was determined and discussed in this work.

\section{EXPERIMENTAL}

\section{Materials}

PLLA and PDLA were polymerized from L-lactide and $\mathrm{D}$-lactide monomers, respectively. ${ }^{20}$ 1-Dodecanol (98\%, Fluka, Switzerland) and stannous octoate $(95 \%$, Sigma-Aldrich, Switzerland) were used as an initiator and a catalyst, respectively. Polymerization temperature and time were $165^{\circ} \mathrm{C}$ and $2.5 \mathrm{~h}$ respectively. PBS was kindly supplied by Multibax Public Co., Ltd., Thailand. PLLA, PDLA and PBS were characterized by a melt flow indexer (Tinius Olsen MP1200), polarimeter (Bellingham and Stanley ADP220) and differential scanning calorimeter (DSC, Perkin-Elmer Pyris Diamond). The properties of PLLA, PDLA and PBS are reported in Table 1. Joncry ${ }^{\circledR}$ chain extender (ADR 4368, BASF, Thailand) was used as received. All reagents used were analytical grade.

Table 1: Properties of PLLA, PDLA and PBS

\begin{tabular}{lcccc}
\hline Sample & $\begin{array}{c}\text { L-enantiomer } \\
\text { content }^{\mathrm{a}}(\%)\end{array}$ & $\begin{array}{c}\mathrm{MFI}^{\mathrm{b}} \\
(\mathrm{g} / 10 \mathrm{~min})\end{array}$ & $\begin{array}{c}\mathrm{T}_{\mathrm{g}}{ }^{\mathrm{c}} \\
\left({ }^{\circ} \mathrm{C}\right)\end{array}$ & $\begin{array}{c}\mathrm{T}_{\mathrm{m}}{ }^{\mathrm{c}} \\
\left({ }^{\circ} \mathrm{C}\right)\end{array}$ \\
\hline PLLA & 96.4 & 21 & 54 & 173 \\
PDLA & 3.2 & 24 & 59 & 176 \\
PBS & - & 30 & -35 & 114 \\
\hline
\end{tabular}

\section{Preparation of scPLA/PBS blends}

PLLA, PDLA, PBS and chain extender were blended at $200^{\circ} \mathrm{C}$ with $100 \mathrm{rpm}$ rotor-speed using a Rheomix Haake internal mixer after drying at $50^{\circ} \mathrm{C}$ under vacuum overnight. The PLLA, PBS and chain extender were first melt blended for $10 \mathrm{~min}$ (step 1), then PDLA and remaining chain extender was added, and the blending was continued for 4 min (step 2). The $50 \%$ of $4.0 \mathrm{phr}$ chain extender was added at each step of melt blending. The PLLA/ PDLA weight ratio of SCPLAs was 50/50. Effects of scPLA/PBS weight ratios (100/0, 95/5 and 90/10) and chain-extender addition (4.0 phr) on blend properties were investigated.

The scPLA/PBS blend films were fabricated using an Auto $\mathrm{CH}$ Caver compression molding machine at $240^{\circ} \mathrm{C}$ for $1.0 \mathrm{~min}$ without any force before compression with 5 ton force for $1.0 \mathrm{~min}$. The obtained film was then cooled to room temperature. The films with $0.2-0.3 \mathrm{~mm}$ in thickness were obtained.

\section{Characterization of ScPLA/PBS blends}

The DSC was used to determined thermal transitions of SCPLA/PBS blends. The blend was melted at $250^{\circ} \mathrm{C}$ for 2 min to eliminate its thermal history before quenching to $0^{\circ} \mathrm{C}$ and then re-heated to $250^{\circ} \mathrm{C}$. The heating rate was $10^{\circ} \mathrm{C} /$ minute.

The thermal decomposition behavior of the ScPLA/PBS blends was measured with a TA-Instrument SDT Q600 thermogravimetric analyzer (TGA). The blends were heated from 50 to $600^{\circ} \mathrm{C}$ at the heating rate of $20^{\circ} \mathrm{C} / \mathrm{min}$ under a $\mathrm{N}_{2}$ flow.

Wide-angle X-ray diffraction (XRD) was used to measure crystalline characteristics of blend films using a Bruker D8 Advance XRD at $40 \mathrm{kV}$ and $40 \mathrm{~mA}$ with CuKa radiation and $3 \% \mathrm{~min}$ scan speed. Degrees of crystallinity $\left(X_{c}\right)$ for homo-PLA $\left(P L A-X_{c, h c}\right)$, stereocomplex-PLA (PLA- $X_{c, s c}$ ) and PBS $\left(P B S-X_{c}\right)$ crystallites were calculated from equations (1)-(3), respectively.

PBS- $X_{c}(\%)=\left[A_{c, P B S} /\left(A_{h c, P L A}+A_{s c, P L A}+A_{c, P B S}+A a\right)\right]$ $\times 100$

$\mathrm{PLA}-\mathrm{X}_{\mathrm{c}, \mathrm{hc}}(\%)=\left[\mathrm{A}_{\mathrm{hc}, \mathrm{PLA}} /\left(\mathrm{A}_{\mathrm{hc}, \mathrm{PLA}}+\mathrm{A}_{\mathrm{sc}, \mathrm{PLA}}+\mathrm{A}_{\mathrm{c}, \mathrm{PBS}}+\mathrm{Aa}\right)\right]$ $\times 100$ $\operatorname{PLA}-\mathrm{X}_{\mathrm{c}, \mathrm{Sc}}(\%)=\left[\mathrm{A}_{\mathrm{sc}, \mathrm{PLA}} /\left(\mathrm{A}_{\mathrm{hc}, \mathrm{PLA}}+\mathrm{A}_{\mathrm{sc}, \mathrm{PLA}}+\mathrm{A}_{\mathrm{c}, \mathrm{PBS}}+\mathrm{Aa}\right)\right]$ $\times 100$

Where $A_{h c, P L A}, A_{s c, P L A}, A_{c, P B S}$ and $A_{a}$ are the integrated intensity peaks for homo-PLA crystallites, stereocomplex-PLA crystallites and PBS crystallites as well as the integrated intensity of the amorphous halo, respectively.

Dynamic mechanical analyzer (DMA, Q800 TA Instruments) was used to determined thermomechanical properties of the blend films. The film with $5 \times 20 \times 0.2 \mathrm{~mm}$ in size was scanned from 40 to $140^{\circ} \mathrm{C}$. The heating rate of $2^{\circ} \mathrm{C} / \mathrm{min}$ was selected. The scan amplitude and scanning frequency were $10 \mu \mathrm{m}$ and $1.0 \mathrm{~Hz}$, respectively.

The measurement of a JEOL JSM-6460LV scanning electron microscopy (SEM) was performed to observe phase separation of the blend films. The 
blend film was immersed in liquid nitrogen before film fracture. The cryo-fractured films were sputter-coated with a thin layer of gold before measurement.

The tensile properties of blend films were determined with a LRX+ Lloyds Universal tensile machine at $25^{\circ} \mathrm{C}$. The film samples $(100 \times 10 \mathrm{~mm})$ were determined with an initial distance between the grips of $50 \mathrm{~mm}$ at an extension speed of $50 \mathrm{~mm} /$ minute. For each sample, five replicates were tested and average values were reported.

\section{RESULTS AND DISCUSSION}

\section{Thermal transitions}

The thermal transitions of ScPLA/PBS blends including $T_{g}, T_{m}$ and cold-crystallization temperature $\left(T_{c c}\right)$ of PBS (PBS- $T_{m}$ ), homo-PLA (PLA$T_{m, h c}$ ) and stereocomplex-PLA (PLA- $T_{m, s c}$ ) crystallites were measured from DSC curves as illustrated in Fig. 1. The Tg and Tcc of ScPLA matrix decreased as increasing of the PBS ratios for both the blends without and with chain extender. This indicates the flexible PBS chains enhanced plasticizing effect in the amorphous regions of ScPLA. ${ }^{13}$ However, the $T_{g}$ and $T_{c c}$ of non-chain-extended blends were lower than the chain-extended blends. The results can be explain by the mobility of PLLA and PDLA chains were limited by branching structures of chainextended blends. ${ }^{21}$

The PBS-T ${ }_{m}$ and PLA-T ${ }_{m, s c}$ peaks of chain-extended blends slightly lower than the nonchain-extended blends. The branching structures also reduced crystal growth. ${ }^{21}$ However, the PLA$\mathrm{T}_{\mathrm{m}, \mathrm{hc}}$ peaks of blends were nearly values in range

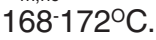

The heat of cold crystallization $\left(\Delta \mathrm{H}_{\mathrm{cc}}\right)$ and heats of melting $\left(\Delta \mathrm{H}_{\mathrm{m}}\right)$ of PBS crystallites (PBS$\left.\Delta \mathrm{H}_{\mathrm{m}}\right)$, PLA homo-crystallites (PLA- $\left.\Delta \mathrm{H}_{\mathrm{m} . \mathrm{hc}}\right)$ and PLA stereocomplex-crystallites (PLA- $\Delta \mathrm{H}_{\text {m.sc }}$ ) obtained from DSC thermograms in Fig. 1 are summarized in Table 2. The $\Delta \mathrm{H}_{\mathrm{cc}}$ of blends decreased steadily as increasing the PBS ratios. This supports the PBS blending enhanced crystallization of the blends according to the literature. ${ }^{16}$ The PBS $-\Delta \mathrm{H}_{\mathrm{m}}$ of the blends with and without chain extender increased as increasing the PBS contents. The PLA- $\Delta \mathrm{H}_{\text {m.hc }}$ were in ranges 33.7-35.8 and 24.5-26.9 J/g for the blends without and with chain extender, respectively. The
PBS- $\Delta \mathrm{H}_{\mathrm{m}}$ and PLA- $\Delta \mathrm{H}_{\mathrm{m} . \mathrm{hc}}$ of the non-chain-extended blends were higher than the chain-extended blends. The results suggested the crystallization of both the PBS and homo-PLA crystallites was suppressed by chain extension. The PLA- $\Delta \mathrm{H}_{\mathrm{m} . \mathrm{sc}}$ of the non-chainextended blends steadily decreased while the chainextended blends did not change (16.4017.7) as the PBS ratios increased.
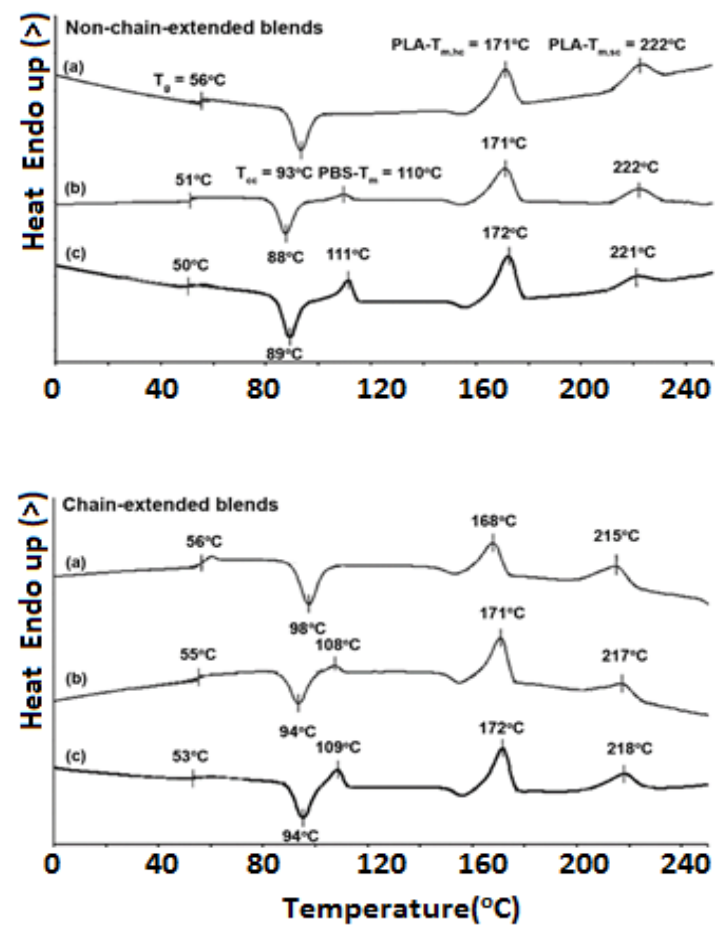

Fig. 1. DSC curves of blends (above) without and (below) with chain extender for ScPLA/PBS weight ratios of (a) $100 / 0$, (b) $95 / 5$ and (c) $90 / 10$

Table 2: DSC results of scPLA/PBS blends

\begin{tabular}{lcccc}
\hline $\begin{array}{l}\text { scPLA/PBS } \\
(\mathrm{w} / \mathrm{w})\end{array}$ & $\begin{array}{c}\mathrm{DH}_{\mathrm{cc}} \\
(\mathrm{J} / \mathrm{g})\end{array}$ & $\begin{array}{c}\mathrm{PBS}-\Delta \mathrm{H}_{\mathrm{m}} \\
(\mathrm{J} / \mathrm{g})\end{array}$ & $\begin{array}{c}\mathrm{PLA}-\Delta \mathrm{H}_{\mathrm{m} . h c} \\
(\mathrm{~J} / \mathrm{g})\end{array}$ & $\begin{array}{c}\mathrm{PLA}-\Delta \mathrm{H}_{\mathrm{m} . \mathrm{sc}} \\
(\mathrm{J} / \mathrm{g})\end{array}$ \\
\hline $\begin{array}{c}\text { Non-chain-extended } \\
\text { blends }\end{array}$ & & & & \\
$100 / 0$ & 30.5 & - & 35.8 & 22.8 \\
$95 / 5$ & 25.2 & 4.8 & 34.4 & 18.6 \\
$90 / 10$ & 22.6 & 12.4 & 33.7 & 9.5 \\
Chain-extended & & & & \\
blends & & & & \\
100/0 & 26.1 & - & 24.5 & 17.6 \\
$95 / 5$ & 19.5 & 2.5 & 26.9 & 17.7 \\
$90 / 10$ & 18 & 7.6 & 26.8 & 16.4 \\
\hline
\end{tabular}

\section{Thermal decompositions}

Thermal decompositions of the scPLA/PBS blends were investigated from thermogravimetric (TG) thermograms (Fig. 2). Both the blend series 
exhibited main thermal-decompositions in range $250-450^{\circ} \mathrm{C}$. The $90 / 10 \mathrm{scPLA} / \mathrm{PBS}$ blends with and without chain extender clearly showed thermal decompositions of PBS components as shoulder curves at higher temperatures. The PBS thermallydecomposed at higher temperature than the PLLA (data not shown). The non-chain-extended blends had slower thermal-decompositions than the chain-extended blends. These results were clearly observed from derivative TG (DTG) curves in Fig. 3. Temperatures of maximum decompositionrate $\left(T_{d, \text { max }}\right)$ peaks were shown.
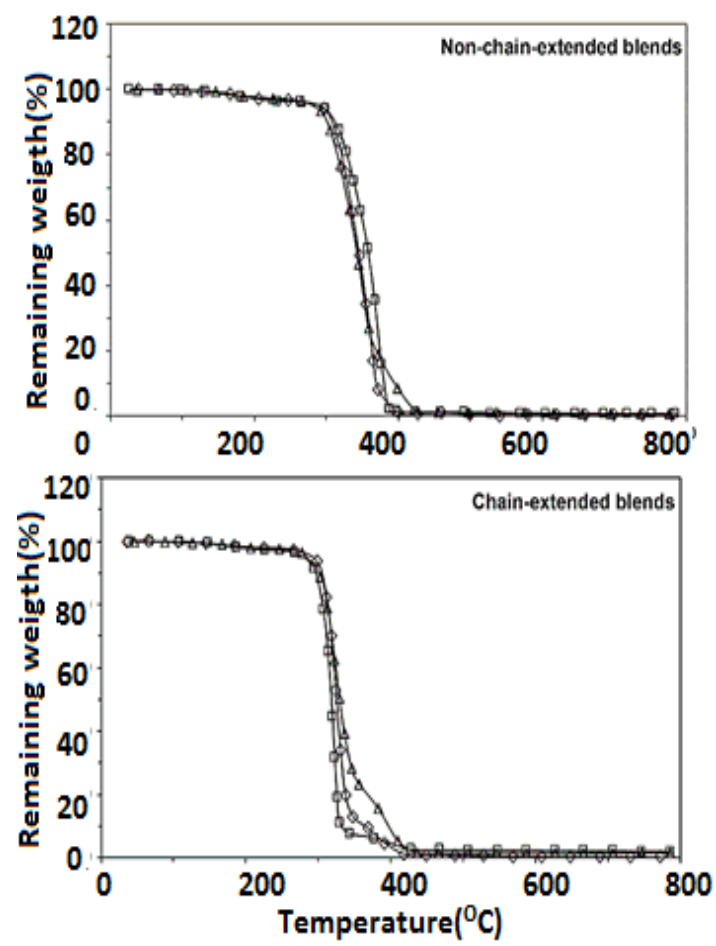

Fig. 2. TG curves of blends (above) without and (below) with chain extender for ScPLA/PBS weight ratios of ( $\square$ ) $100 / 0,(\bullet)$ 95/5 and $(\Delta)$ 90/10

For the non-chain-extended blends, the $T_{d, \max }$ peaks of scPLA and PBS components were in ranges $352-374^{\circ} \mathrm{C}$ and $400-403^{\circ} \mathrm{C}$, respectively. The $T_{d \text {,max }}$ of scPLA matrix significantly moved to lower temperature when the PBS ratio was increased. The PBS chains penetrated between PLLA-PLLA, PDLA-PDLA and PLLA-PDLA chains to decreases their intermolecular interactions. The results indicate the scPLA/PBS blends were partially miscible. In addition the $T_{d, \max }$ peaks of both scPLA and PBS components of the chain-extended blends were lower than the non-chain-extended blends.
The branching structures of chain-extended blends suppressed intermolecular interactions of polymer chains. ${ }^{17}$ It should be noted that the $T_{d, \max }$ of ScPLA matrix of chain-extended blends exhibited at higher temperature for the higher PBS content. The results indicated the chain extension could improve thermal stability of the SCPLA matrix by chain extension with the higher thermal-stability PBS molecules.

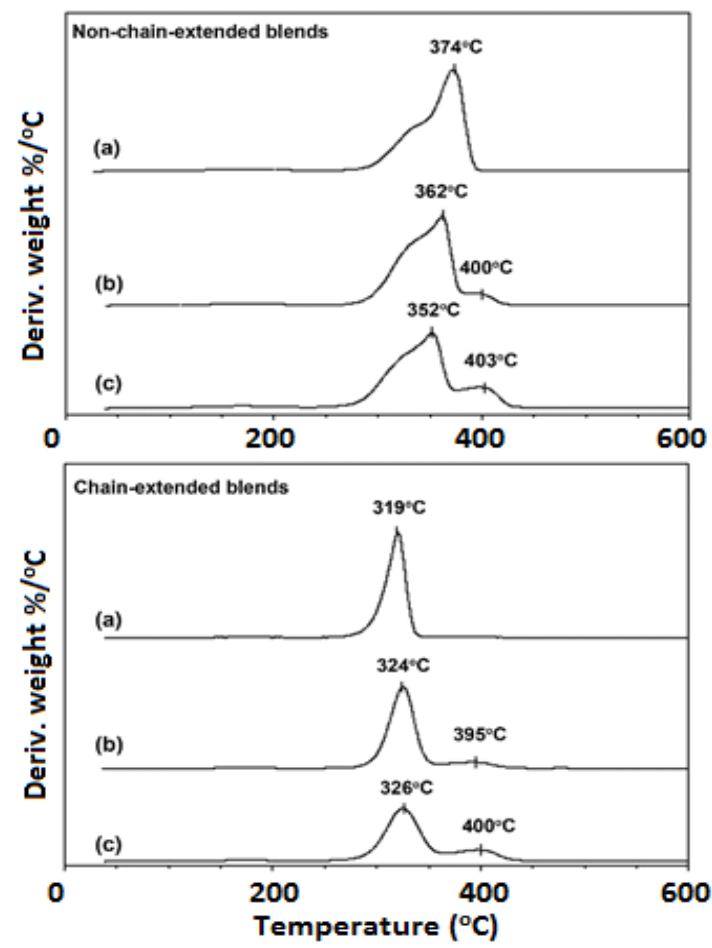

Fig. 3. DTG thermograms of blends (above) without and (below) with chain extender for ScPLA/PBS weight ratios of (a) $100 / 0$, (b) $95 / 5$ and (c) $90 / 10$. (Td,max peaks as shown)

\section{Structures of blend crystallites}

The XRD profiles of blend films were shown in Fig. 4 to investigate their crystalline structures. The 100/0 scPLA/PBS in Fig. 4 (above, a) showed only diffraction peaks at $12^{\circ}, 21^{\circ}$ and $24^{\circ}$ assigned to PLA stereocomplex crystallites. ${ }^{22}$ It had no diffraction peaks of PLA homo-crystallites at $16.5^{\circ}$ and $19.0^{\circ} .^{22}$ This result differs with previous DSC result in Fig. 1 (above, a) that the PLA-T ${ }_{m, h c}$ peak was also observed. This may be explained by homo-PLLA and homo-PDLA crystallites of film matrix could have not formed during film forming by compression force at high temperature $\left(T>P L A-T_{m, n c}\right) \cdot{ }^{23}$ In addition, the PLA homo-crystallization could be have occurred during DSC heating scan without external forces. ${ }^{20}$ The $95 / 5$ and $90 / 10$ scPLA/PBS blend films exhibited 
diffraction peaks at $19.7^{\circ}, 22.0^{\circ}$ and $29.3^{\circ}$ attributed to PBS crystallites. ${ }^{16}$ These peak intensities increased as the PBS ratios increased.

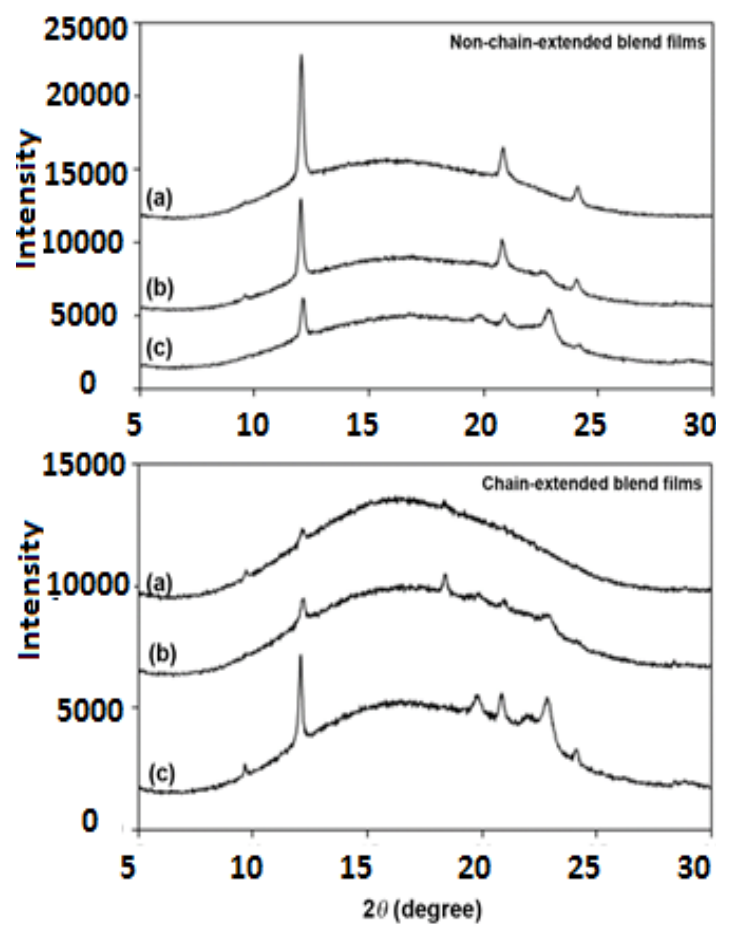

Fig. 4. XRD patterns of blend films (above) without and (below) with chain extender for scPLA/PBS weight ratios of (a) $100 / 0$, (b) $95 / 5$ and (c) $90 / 10$

The PLA- $X_{c, s c}$ and PBS- $X_{c}$ values are reported in Table 3. The PBS- $X_{c}$ values increases with the PBS ratio for both the blend-film series. For the non-chain-extended blend films, the decreasing in PLA- $X_{c . s c}$ values was found when the PBS ratio was increased. This suggests the PBS blending inhibited stereocomplexation of non-chain-extended PLA matrix. The PLA- $X_{c . s c}$ values of scPLA film decreased from $9.2 \%$ to $0.7 \%$ when the ScPLA was chain-extended. The stereocomplexation of PLA matrix was inhibited by branching structures of blend films with chain extension.20 The PLA- $\mathrm{X}_{c . s c}$ of blend films with chain extension increased as the PBS ratio increased. The PBS could act as nucleating sites for PLA stereocomplexation. More free-volumes of branched structures of chain-extended blend films enhanced chain mobility for stereocomplex crystallization with PBS nucleating sites.

\section{Thermo-mechanical properties}

The thermo-mechanical properties from DMA analysis have been widely used to investigate heat-resistant property of PLLA and scPLA from changes of storage modulus and $\tan \delta .{ }^{24-27}$ The storage modulus dramatically dropped in the region of glassy-to-rubbery transition for the poor heat-resistant PLLA due to its low $X_{c}$. After that, the storage modulus increases again during DMA heating because of PLLA cold-crystallization. ${ }^{24}$ The PLLA with low $X_{c}$ usually obtained from melt processes because of PLLA is slow crystallization rate. The annealed PLLA with high Xc maintained its stiffness on the $T_{g}$ region to achieve its high heatresistance. ${ }^{27}$

Table 3: Xc values of scPLA/PBS blend films from XRD

\begin{tabular}{ccc}
\hline scPLA/PBS $(w / w)$ & PLA-X $_{c . s c}(\%)$ & PBS- $_{c}(\%)$ \\
\hline Non-chain-extended blends & & \\
$100 / 0$ & 9.2 & - \\
$95 / 5$ & 7.3 & 2 \\
$90 / 10$ & 4.3 & 7.1 \\
Chain-extended blends & & \\
$100 / 0$ & 0.7 & - \\
$95 / 5$ & 2.3 & 2.2 \\
$90 / 10$ & 4.1 & 6.2 \\
\hline
\end{tabular}

Figure 5 shows storage modulus of the scPLA/PBS blend films. The storage modulus of blend films without chain extender [Fig. 5 (above)] decreased from 4252-4536 MPa to 36-52 MPa when the temperature was increased up to $75^{\circ} \mathrm{C}$ before raising up during DMA heating. This indicates the heat resistance of non-chain-extended ScPLA/PBS blend films did not change in significant by PBS blending. From Fig. 5 (below), the chain-extended ScPLA film was largely dropped on storage modulus [see black line in Fig. 5 (below)]. This is due to the chain-extension reaction reduced the PLA- $\mathrm{X}_{\mathrm{c}, \mathrm{sc}}$ of scPLA films from $9.2 \%$ to $0.7 \%$ as reported in Table 3. However, the storage modulus in the region of glassy-to-rubbery transition of chainextended ScPLA film was significantly improved by $5 \%$ and $10 \%$ PBS blending [see red and blue lines, respectively, in Fig. 5 (below)]. This is due to the PLA- $X_{c, s c}$ of chain-extended blend films were higher; $2.3 \%$ and $4.1 \%$ for $95 / 5$ and $90 / 10$ scPLA/ PBS blend films, respectively. The results indicated that the stiffness and heat-resistant property of the chain-extended ScPLA films can be improved by blending with PBS. 

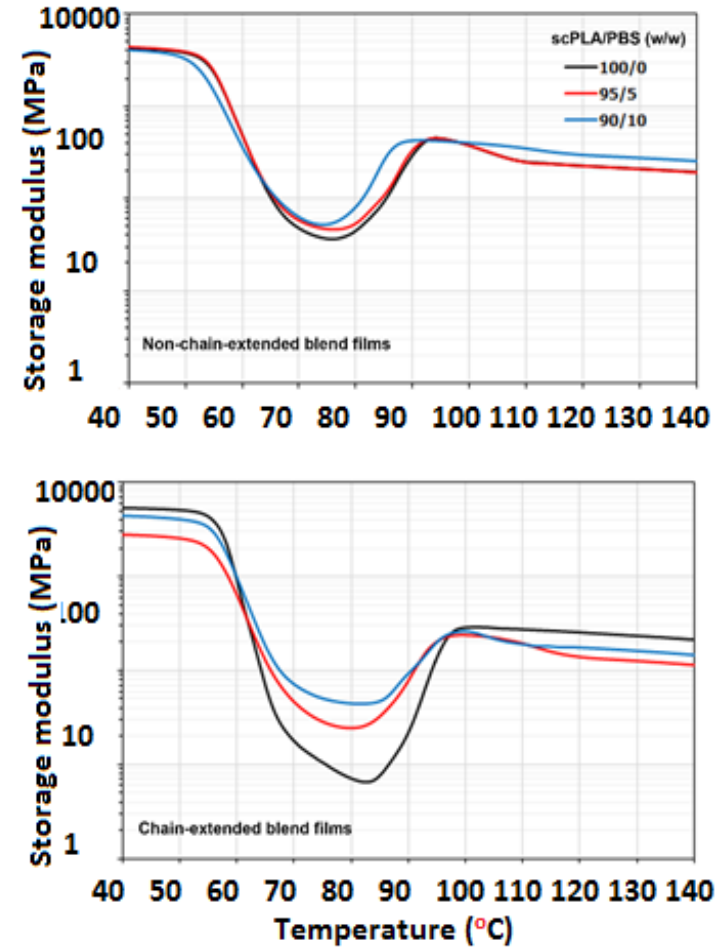

Fig. 5. Storage modulus from DMA of blend films (above) without and (below) with chain extender with various SCPLA/PBS ratios

The heat resistance of ScPLA/PBS blend films was also elucidated from $\tan \delta$ curves as shown in Fig. 6. The area of $\tan \delta$ peak indicates the damping ability; the ability of samples to absorb and dissipate energy. ${ }^{26,27}$ The areas underneath the $\tan \delta$ peak of the blend films without chain extension for various scPLA/PBS ratios [Fig. 6 (above)] were similar suggested the heat resistance of these films was similar. For the blend films with chain extension, the area underneath the $\tan \delta$ peak of the scPLA film [see black line in Fig. 6 (below)] was the largest. When $5 \%$ and $10 \%$ PBS were blended, the peak areas of the blend films significantly decreased [see red and blue lines, respectively, in Fig. 6 (below)]. The results indicated the chain mobility of ScPLA matrix was restricted on the glassy-to-rubbery transition. Therefore the stiffness of chain-extended ScPLA films was enhanced by PBS blending. It could be confirmed that the PBS blending enhanced stiffness and heat resistant properties of the chain-extended scPLA films.
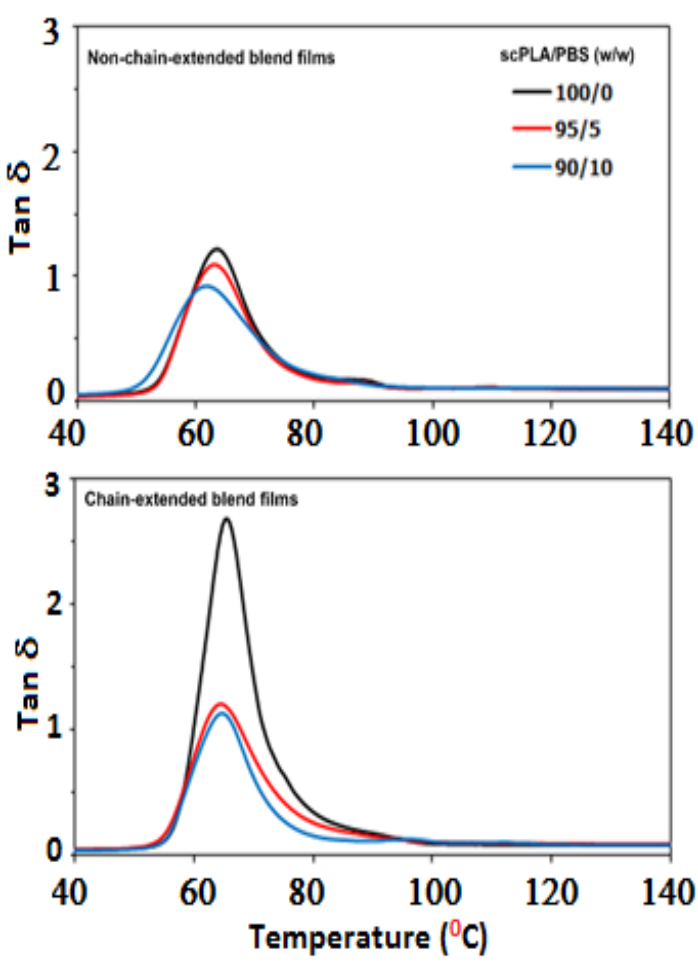

Fig. 6. Tan $\delta$ from DMA of blend films (above) without and (below) with chain extender with various SCPLA/PBS ratios

\section{Phase separation}

Phase separation between continuous scPLA matrix and dispersed PBS phases was observed from film cross-sections as shown in Fig. 7. The PBS particles of all the blend films were nearly spherical in shape with good distribution. However, many voids were found for the nonchain-extended blend films with $5 \%$ and $10 \%$ PBS [Fig. 7 (left, b) and (left, c)]. This suggests poor phase-compatibility in the blend films. 15 The debonded PBS particles may be removed out during film cryo-fraction. The blend films with chain extender presented fewer voids. Therefore chain extension enhanced phase compatibility of the SCPLA/PBS blends. This could be explained by the molecules of chain-extended blends consisted of both PLA (PLLA and PDLA) and PBS chains. These molecules could act as compatibilizers to enhance phase adhesion of the scPLA/PBS blends. ${ }^{14}$

\section{Tensile properties}

Average tensile properties of the blend films were shown in Fig. 8. It was found that stress at break steadily reduced and strain at break slightly improved as increasing the PBS ratios. This is due 
to the high flexibility of PBS. ${ }^{16}$ The blend films with chain extension exhibited more stress and strain at break than without chain extension for the same scPLA/PBS blend ratio. The long-chain branching structures improved these tensile properties. However, the the PBS and chain extender did not change Young's modulus of the blend films.

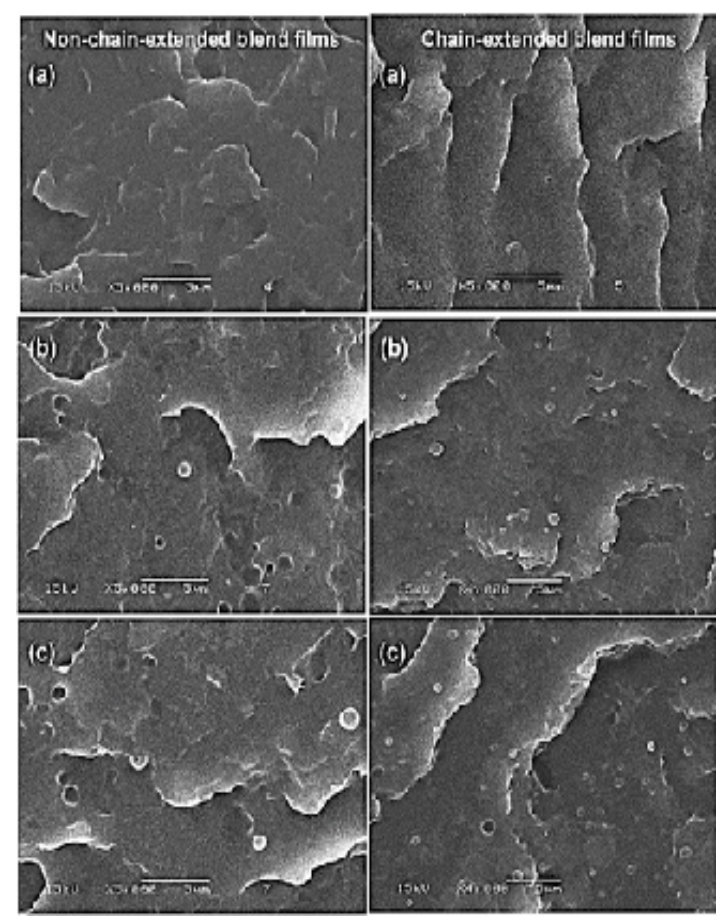

Fig. 7. SEM images of film cross-sections (left column) without and (right column) with chain extension for SCPLA/ PBS weight ratios of (a) 100/0, (b) 95/5 and (c) 90/10 (All bar scales $=5.0 \mu \mathrm{m}$ )

\section{CONCLUSION}

The blends of SCPLA/PBS without and with chain extender were prepared by melt blending. The PBS blending enhanced chain mobility of SCPLA matrix in an amorphous phases to decreases its $T_{g}$ and $\mathrm{T}_{c c}$. However, both the $\mathrm{T}_{g}$ and $\mathrm{T}_{\mathrm{cc}}$ of the blend films shifted to higher temperature by chain extension. The phase adhesion between scPLA matrix and dispersed

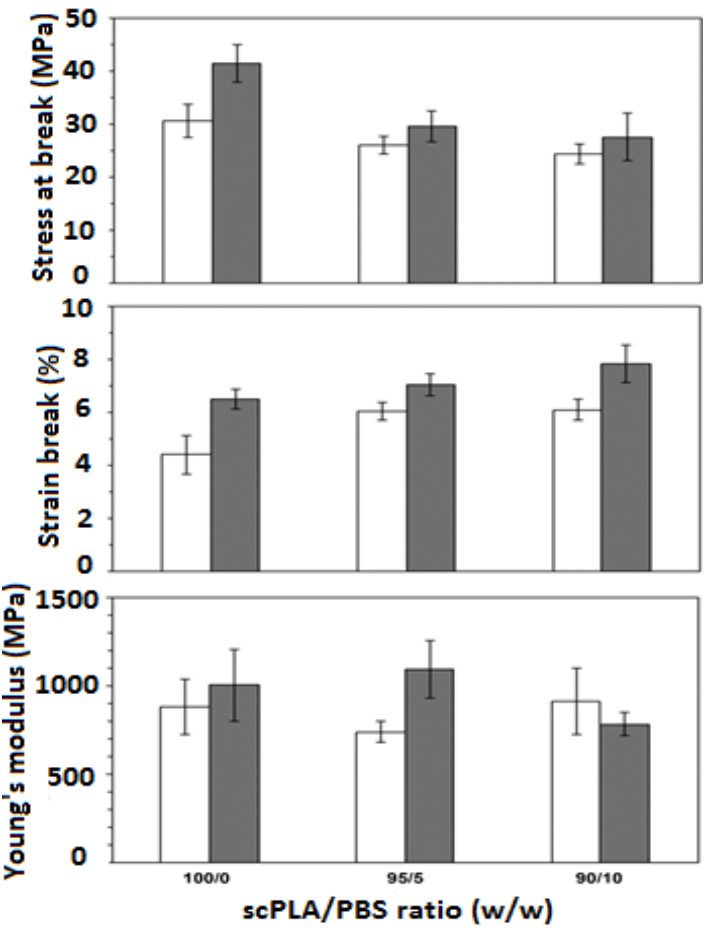

Fig. 8. Tensile properties of blend films ( $\square$ ) without and (ם) with chain extender for ScPLA/PBS weight ratios of (a) $100 / 0$, (b) $95 / 5$ and (c) $90 / 10$

PBS particles could be improved by chain-extension reaction. The PBS blending improved the heat resistance of chain-extended scPLA films. Finally, chain extender enhanced film extensibility of blend blends. These results suggest that more flexible and good heat resistant SCPLA/PBS blend films with chain extender can be used for development of high performance bioplastics.

\section{ACKNOWLEDGEMENT}

This research was funded by Mahasarakham University (grant no. 6105032).

\section{Conflict of Interest}

The authors declare that there is no conflict of interest.

\section{REFERENCES}

1. Rocca-Smith, J.R.; Whyte, O.; Brachais, C.; Champion, D.; Piasente, F.; Marcuzzo, E.; Sensidoni, A.; Debeaufort, F.; Karbowiak, T. ACS Sustain. Chem. Eng., 2017, 5, 2715-2762.

2. Castro-Aguirre, E.; Auras, R.; Selke, S.;
Rubino, M.; Marsh, T. Polym. Degrad. Stab., 2018, 154, 46-54.

3. Silva, D.; Kaduri, M.; Poley, M.; Adir, O.; Krinsky, N.; Shainsky-Rotiman, J.; Schroeder, A. Chem. Eng. J., 2018, 340, 9-14. 
4. Nootsuwan, N.; Sukthavorn, K.; Wattanathana, W.; Jongrungruangchok, S.; Veranitisagul, C.; Koonsaeng, N.; Laobuthee, A. Orient. J. Chem., 2018, 34(2), 683-692.

5. Yang, Y.; Zhang, L.; Xiong, Z.; Tnag, Z.; Zhang, R.; Zhu, J. Sci. China Chem., 2016, 59(11), 1355-1368.

6. Tsuji, H. Adv. Drug Deliv. Rev., 2016, 107, 97-135.

7. Cui, C.-H.; Yan, D.-X.; Pang, H.; Jia, L.-C.; Xu, X.; Yang, S.; Xu, J.-Z.; Li, Z.-M. Chem. Eng. J., 2017, 323, 29-36.

8. Pasee, S.; Cheerarot, O.; Baimark, Y. Orient. J. Chem., 2015, 31(3), 1551-1558.

9. Li, Y.; Xin, S.; Bian, Y.; Dong, Q.; Han, C.; Xu, K.; Dong, L. RSC Adv., 2015, 5, 24352-24362.

10. Jiang, L.; Shen, T.; Xu, P.;Zhao, X.; Li, X.; Dong, W.; Ma, P.; Chen, M. e-Polymers., 2016, 16(1), 1-13.

11. El-Khodary, E.; Fukui, Y.;Yamamoto, M.;Yamane, H. J. Appl. Polym. Sci., 2017, 134, 45489.

12. Ojijo, V.; Ray, S.S.; Sadiku, R. ACS Appl. Mater. Interfaces., 2013, 5, 4266-4276.

13. Pivsa-Art, W.; Fujii, K.; Nomura, K.; Aso, Y.; Ohara, H.; Yamane, H. J. Appl. Polym. Sci., 2016, 133, 43044.

14. Salehiyan, R.; Ray, S.S.; Bandyopadhyay, J.; Ojijo V. Polymers., 2017, 9, 350.

15. Fenni, S.E.; Monticelli, O.; Conzatti, L.; Doufnoune, R.; Stagnaro, P.; Naddaoui, N.; Cavallo, D. Express Polymer Letters., 2018, 12(1), 58-70.
16. Zhang, X.; Liu, Q.; Shi, J.; Ye, H.; Zhou, Q. J. Polym. Environ., 2018, 26, 1737-1744.

17. Baimark, Y.; Cheerarot, O. Orient. J. Chem., 2015, 31(2), 635-641.

18. Murariu, M.; Paint, Y.; Murariu, O.; Raquez, J.-M.; Bonnaud, L.; Dubois, P. J. Appl. Polym. Sci., 2015, 132, 42480.

19. Tuna, B.; Ozkoc, G. J. Polym. Environ., 2017, 25, 983-993.

20. Baimark, Y.; Kittipoom, S. Polymers., 2018, 10, 1218.

21. Chen, P.; Yu, K.; Wang, Y.; Wang, W.; Zhou, H.; Li, H.; Mi, J.; Wang, X. J. Polym. Environ., 2018, 26, 3718-3730.

22. Lee, S.; Kimoto, M.; Tanaka, M.; Tsuji, H.; Nishino, T. Polymer., 2018, 138, 124-131.

23. Pan, G.; Xu, H.; Ma, B.; Wizi, J.; Yang, Y. J. Mater. Sci., 2018, 53, 5490-5500.

24. Vadori, R.; Mohanty, A.K.; Misra, M. Macromol. Mater. Eng., 2013, 298, 981-990.

25. Nuzzo, A.; Coiai, S.; Carroccio, S.C.; Dintcheva, N.T.; Gambarotti, C.; Filippone, G. Macromol. Mater. Eng., 2014, 299, 31-40.

26. Srithep, Y.; Pholharn, D.; Turng, L.-S.; Veang-in, O. Polym. Degrad. Stab., 2015, 120, 290-299.

27. Zhang, X.; Meng, X.L.; Li, G.; Liang, N.; Zhang, J.; Zhu, Z.; Wang, R. J. Appl. Polym. Sci., 2016, 133, 42999. 